\title{
Network Diversity Structure, Closeness And InNOvation OF SOUTH AFRICAN MiCRO-ENTREPRENEURS
}

Eliada Griffin-EL

Graduate School of Business, University of Cape Town

Accepted: January 2014

\begin{abstract}
This study qualitatively explores the embeddedness of the innovation process of South African microbusinesses by investigating how small local entrepreneurs in the Greater Johannesburg area utilise their social networks to source entrepreneurial value. A comparative grounded theory analysis enabled the original conceptualisation of Network Diversity Structure and formulates the central proposition that the network dimensions of diversity and closeness enable the innovation process among manufacturing microbusinesses more so than in service microbusinesses. Furthermore, the study proposes that both a structural and relational/experiential dimension of closeness, enables micro-entrepreneurs to create meaning and knowledge collaboratively with other entrepreneurs and actors. This socially facilitated process of exchanging ideas, information, and resources is central to the innovation process of firms traditionally limited by both their size and historical social institutions.
\end{abstract}

Key words: social networks; micro-entrepreneurship; social embeddedness; innovation

JEL: D85, J15, L26, M13

1

\section{Introduction}

Micro-sized but formally registered businesses of the South African entrepreneurial landscape occupy a particular place on the country's development agenda. As micro-enterprises, they face the well-known challenges of achieving scale and productivity levels; yet, as formally registered businesses, they serve as a bridge between the central and peripheral markets that both constitute the South African economy. With their failure rates presumed to be high, yet their success presumed to be important, understanding how they facilitate their entrepreneurial process while having limited capacity becomes a question of both intrigue and development implications for economic inclusivity.

The purpose of this study is to explore the structural embeddedness of South African microbusinesses - and to better understand how they have engaged with the social relationships in which they are embedded in order to advance and support their entrepreneurial activity. This study is driven by the initial open-ended research question, "Is there value in microbusinesses' relationships that enable them to entrepreneurially function - and even excel - beyond their resource and capacity constraints?' Inspired by assumptions of the economic sociological literature, the analysis attempts to visually depict the shape of their ego-centric networks, in order to convey the perceptual distance or closeness that they bear with various entities. Additionally, the study provides a conceptualisation of the diversity relational types and entrepreneurial value they contribute.

Conducted as a comparative grounded theory analysis, data was collected via the indepth interviews of 30 formally registered microbusinesses of black South African entrepreneurs from the (clothing) manufacturing (set I) and service sectors (set II). The study took place in Greater Johannesburg in partnership with The Business Place. All firms included/ involved? employed 10 or less employees.

As suggested by findings of the qualitative analysis, the study presents the central proposition that the innovation process involved in a microbusiness's value chain is facilitated by a high degree of closeness with a diverse set of relationships. Microenterprises in the 
clothing manufacturing sector appear to have a higher degree of closeness with a diverse array of actors, which enables them to undergo an interaction-oriented innovation process as a key part of their entrepreneurial process. The data did not present similar evidence to suggest the service microenterprises' networks support the same phenomenon. Moreover, the data emphasises the relational nature of the innovation processes in design and production by engaging in a collaborative creation process with similar and different microbusinesses. Hence relationships with these individuals tend to be highly valued and enacted frequently, facilitating a closeness. Network diversity structure (NDS), an original core concept of the emergent theoretical framework, refers to the degree of closeness, diversity, and number of relationship types that constitutes the structural shape of ties. As in the grounded theory tradition, the discussion explores how the findings are supported by - and contribute to - the literature on networks and innovation.

\section{2}

\section{Review of the literature}

Social embeddedness and social capital literature suggest that relations, interactions, and norms inform economic behavior that shapes the market. In turn, entrepreneurs influence - and are influenced by - their engagement with the broader society within which they are embedded (Granovetter, 1985; Giddens, 1986; Woolcock, 1998; Grootaert, Narayan, Jones, \& Woolcock, 2003; Dobbin, 2004; Urban, 2011). At the core is the assumption that an economic actor makes his or her decisions resulting from a negotiation of their personal utility and the information and norms they draw from their engagement with others (Granovetter, 1985). The social embeddedness perspective moves away from the individual- or organisational-centered outlook of entrepreneurship and provides a view by which to examine entrepreneurs in respect to their relational context (Portes \& Sensenbrenner, 1993; Portes, 1998). Network studies particularly examine "the structure of the relations between social actors and how patterns in those relations influence a variety of outcomes," (Stuart \& Sorenson, 2005:233).
Also referred to as a structural analysis, network studies assist in unveiling the restrictions and opportunities that an actor inherits as a result of the relationships they are embedded within (Garcia, 2006). Hoang and Antoncic (2003) acknowledge the need for theory building that captures the nexus between outcome- and process-oriented studies. This speaks to the dynamism of networks and their ability to support a small firm's evolving needs (Hite \& Hesterly, 2001). It is in this gap of networks' role in the entrepreneurial process that this study hopes to contribute.

This study draws from social capital literature's broad distinctions across relationship types. Horizontal relationships - or bonds and bridges - loosely describe relationships between entities from close, familial settings and similar characteristics and relationships between parties of different circles or communities, respectively (Gittell \& Vidal, 1998; Woolcock \& Narayan, 2000). Vertical relationships, termed as linkages, refer to relationships between entities and institutions (Woolcock, 1998, 2002). Bonds, bridges, and linkages will provide the conceptual language and theoretical reference point of the idea of diversity in networks.

Apart from the entrepreneurial process, the empirical arm of the literature tends to focus on the characteristics influencing, resources gained from, or the composition of the network structure. Attributes such as culture (Greve \& Salaff, 2003; Klyver, Hindle, \& Meyer, 2008), economic sector (Spence, Schmidpeter, \& Habisch, 2003), and business phase (Klyver et al., 2008) of entrepreneurs have been featured. Size (Barr, 1995; 2002); global exposure (Mcdade \& Spring, 2005); gender (Kuada, 2009; Rutashobya, Allan, \& Nilsson, 2009); one's 'identity landscape' (Pingle, 2001); and ethnicity (Bruce, 2003) are also highlighted entrepreneurial attributes that lend to network structural variation. Broader environmental factors - such as the degree of regional development (Garcia, 2006) or economic liberalisation (Meagher, 2006) - have also been recognised as a contributing variable. Resource- based network studies highlight network gains - such as knowledge acquisition and production capacities (Yli-Renko, Autio, \& Sapienza, 2001); security (Barr, 1995, 2002); and innovation aspects (Barr, 1995, 1002; 
Bakker, Oerlemans, \& Pretorius, 2008). Social arrangements such as familial ties (Luo, 1997; Fafchamps \& Minten, 2002); sub-contracting ties (Luo, 1997); home-based networks (Zhou, Wu, \& Luo, 2007); and extra-, inter-, and intra-firm linkages (Yeung, 1997) describe the network composition that even enable a small firm's adjustment to global changes (Chen, 2009; Lu \& Beamish, 2001; Yeung, 1997; Zhou et al., 2007).

Although the literature appears to be growing, there is still much more to learn about how network structure facilitates the entrepreneurial process- particularly with small, emerging firms within African economies which are increasingly opening and connecting to a global economy (Naude \& Havenga, 2005). Studying the formally registered microbusiness community within the backdrop of a dynamic emerging economy such as South Africa bears its own distinct significance (Human, 2009). The relational structures of such firms embody both formal and informal ties that span the formal and peripheral economies. Hence, an inductive, exploratory approach is applied in order to grasp the network characteristics that are embedded within diverse economic domains.

3

\section{Methodology}

\subsection{Grounded theory analysis}

Data was analysed using the grounded theory methodology. Entrepreneurial research in general, as Makela and Turcan (2007) suggest, has room to be enriched by the capturing of nuanced factors. Grounded theory analysis, like most qualitative analyses, guides the investigator towards identifying abstract themes from the raw data. Grounded theory's distinguishing objective is to derive an original 'theory' from the data which conceptually captures the intrinsic process of the phenomenon being studied (Glaser \& Strauss, 1967). Beyond the initial phase of thematic coding, analysis also entails a constant comparison and categorisation of codes to gradually reveal the main concepts of the emerging theory. Upon reaching theoretical saturation, the central conceptual category is identified to which all other conceptual categories relate to build an explicatory narrative of the phenomenon. Propositions can be formed to be tested in future studies. (Glaser \& Strauss, 1967; Strauss \& Corbin, 1990).

\subsection{Research participants}

Data was collected in June to August of 2008 via in-depth, open-ended interviews with thirty micro-sized South African firms. The sample was constructed via random selection of willing, available firms from The Business Place Opportunity Exchange Database, The Johannesburg Fashion Week listings, and to a lesser extent, the snow-balling method via referrals. 'Micro' in this study is defined as firms hiring ten or less full-time employees. All the businesses were formally registered in South Africa and all the entrepreneurs were black South Africans. Approximately 47 per cent of the subjects interviewed hired at least one employee and 30 per cent spoke to having at least one business partner. The median age of the business organisations was three years, ranging from a minimum of 4 months to a maximum of 12 years. More than 50 per cent of the entrepreneurs themselves fell within the ages of 25 and 30, the youngest being 21 and the oldest more than 50. 47 per cent of entrepreneurs operated their businesses from the Central Business District of Johannesburg. The remaining were based in the broader Johannesburg metropolitan area consisting of the surrounding townships, suburbs, and towns - such as Soweto, Vosloorus, Benoni, Alberton, and Vereeninging in the Vaal.

The broad spectrum of enterprises of various ages that are featured in the study hold the commonality of being microenterprises. In this study, their small scale is primarily measured in terms of employment, where all firms have ten or less employees. The broad spectrum allows for the analysis to identify patterns common across the relational structure of micro-enterprises, despite the duration of time that have been in operation. In this manner, the variable of size is kept constant. Extended analysis, as well as literature, does suggest that the structure of networks for even small-scale enterprises varies by the age of the firm. Nonetheless, considered beyond the 
scope of this study, the analysis focuses upon cross-cutting network trends across microfirms of all ages for this phase of the analysis.

Of all the subjects interviewed, data from twenty-four firms was analysed. Exactly half of the set are from the clothing/fashion manufacturing industry. The other 50 per cent was comprised of firms from the service industries - five construction firms, four media and publicity firms, and three health and beauty enterprises. Firms which were selflabeled 'construction firms' mostly provided services of customised renovation and design services to both private and public property. Such work is categorised under 'specialised consumer discretionary services,' according to the Standard and Poor's Global Industry Classification Standard, and hence, was noted as 'services' in this study (2008). Most interviews were held either on the first floor of The Business Place Headquarters in Johannesburg $\mathrm{CBD}$, while others were conducted at the location of the business or an alternative location chosen by the entrepreneur.

\subsection{Data collection}

The interview instrument used for this study was a revised version of Abigail Barr's original Entrepreneurial Network Diversity Questionnaire used for her study of the Ghanaian manufacturing industry in Accra, Ghana (1995). South African entrepreneurs were asked of their relationship with eight entities - 1) similar entrepreneurs; 2) different entrepreneurs; 3) entrepreneurs in other South African provinces; 4) entrepreneurs in other countries; 5) immigrant entrepreneurs; 6) larger businesses; 7) government; and 8) financial institutions. The following five questions were asked about the relationship with each of the aforementioned entities:

a How many people do you know in this particular group?

b Is this (are these) relationship valuable to your business? If so, how?

c How often do you communicate with contacts in this group?

d When did you meet the first contact in this group?

e How did you meet them?
As a key initiating question, I asked the entrepreneurs to 'tell their story.' This 'story telling' provided a richness of data that largely illustrated the process of their development, the relationships along their journey, and an elaboration of the subject's context through their own voice.

\section{4}

\section{Data analysis}

\subsection{Diversity of relationships: bonds, bridges, and linkages}

In alignment with the literature, and for the sake of simplification, the diversity of relationships is loosely categorised as bonds, bridges, and linkages. Although entrepreneurs were asked about their relationships with eight types of entities, qualitative data unveiled that entrepreneurs interacted with each type of entity in multiple ways. Hence, 16 distinct bond, bridge, and linkage relationships were derived from the data, each bearing their own functionality and contributing their unique value to the entrepreneur's experience. This differentiation was useful in dispelling the monolithic perception of broadly labeled groups, such as 'different types of entrepreneurs' or 'government.' Since listing the specifics of all 16 relationships is beyond the scope of this paper, the structural depiction of their network will simply convey this diversity in terms of bonds, bridges, and linkages, providing details of the most prominent relationships. Each relational type is differentiated by the node's geometric shape.

\subsection{Network Diversity Structure}

The concept of Network Diversity Structure (NDS) refers to the structural arrangement of the diverse relationships within the small entrepreneurs' networks. NDS in this study was comprised of three defining properties, as derived from the data:

\subsubsection{The diversity of relationships.}

The primary conceptual identities of - and the sub relationships within - the categories of different bonds, bridges, and linkages derived from the data via the coding analysis. 


\subsubsection{The relative number of relationships for every type.}

Dimensions of this property (i.e. many, some, few, and none) were assigned a summative scale (i.e. 3,2,1,0 respectively) as well as geometric shapes of consecutive size order in order to visually depict a scale of group size. In other words, a large number of contacts were depicted by geometrically-shaped nodes of a corresponding size.

\subsubsection{The relative closeness of the ties to the entrepreneur in the network.}

The conceptual property of 'the closeness of ties,' is measured here by how often they communicate and how valuable the relationship is to their business. Closeness refers to the distance of a relationship to the entrepreneur based upon 1) how much he or she values the relationship, and 2) how much time is spent with the entity. To visually convey the close relationships in a network, the indicator combines (by averaging) both the relationship properties of value and frequency. A summative scale is assigned to the dimensions of each of the properties so as to calculate the average. The calculated average of the Value and Frequency dimensions corresponds with different spheres of the entrepreneur's network (see Figures 1 and 2), which are also assigned a summative scale. The study proposes, as suggested by the data, that the less the value and/or the lower the frequency of communication, the farther the relationship. Visually, a less close relationship is conveyed by greater distance - or a longer line - between the central entrepreneur (the white circle in the middle) and the contact. The data does not sufficiently suggest that either the Value or Frequency variable influences entrepreneurial development more than the other, and hence, are weighed the same. Nonetheless, this aspect is worthy of further examination in future studies.

The NDS diagrams for both clothing manufacturing (Entrepreneur Set I) and service entrepreneurs (Entrepreneur Set II) is conveyed in Figure 1 and 2, respectively.

Figure 1

Network Diversity Structure of Entrepreneurship Set I

Network Diversity Structure of Entrepreneur Set I

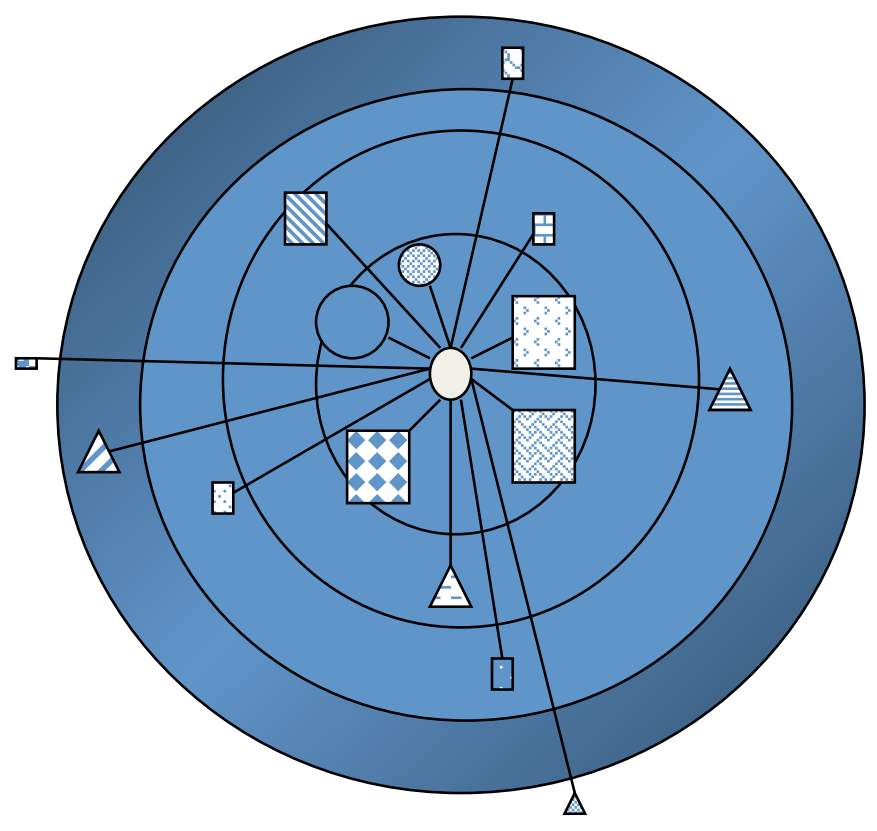

Property: Number

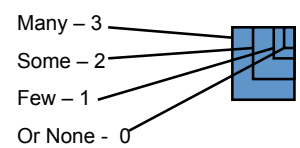

Property: Value

Very valuable -1

Valuable -2

Somewhat valuable -3

Not valuable -4

\section{Property: Frequency}

Very often -1

Often -2

Sometimes -3

Rarely - 4

Not at all -5

Legend

Bonds

Bridges

Linkages 


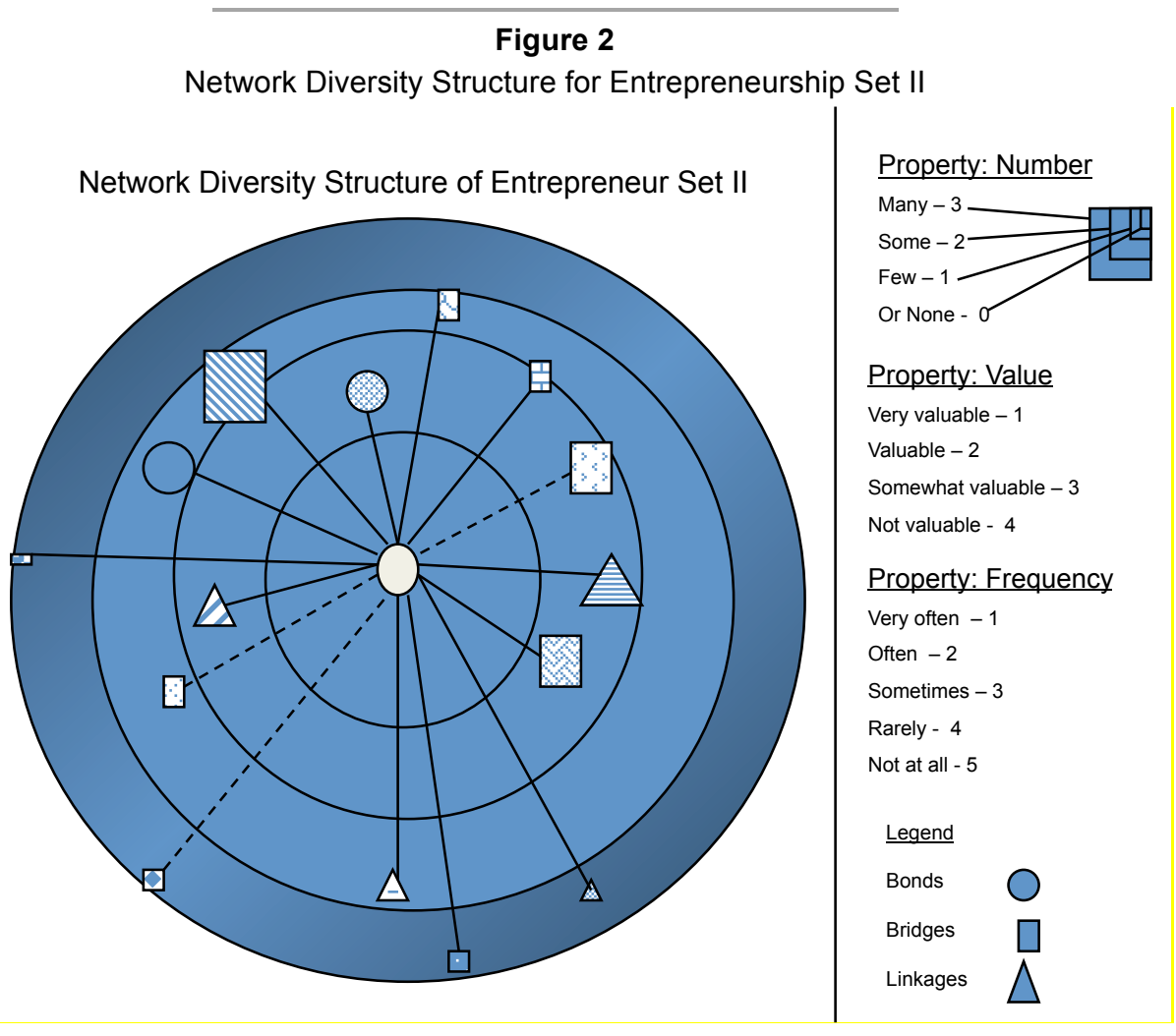

The NDS for each set of entrepreneurs reveals a visible contrast in closeness of their most prominent relationships. Similarly, both network structures also reveal comparable farness of the same relationships. The following section will compare the structure of both networks in its most obvious differences. Subsequent parts of the discussion will then highlight the identity of the innermost cluster of relationships depicted in both networks in order to further unveil the nature of diversity and the process to which they contribute value.

\subsection{Exploring the conceptual closeness of South African microbusiness' networks}

The contrast between the structural depictions of the networks portrays an obvious difference in the general distance of relationships from the central entrepreneur. As made clear by the contrast in the images, the obvious difference between both network diagrams is that of the closeness of the relationships to the central actor, and inversely, the farness of the relationships visually residing in the outer rings of the depictions. It is to be noted, that this study conceptualises closeness derived from qualitative data and analysis. Conceptually, based upon the data, a relationship that is close to the entrepreneur is that with which the entrepreneur engages and communicates frequently as well as values highly in regards to their business. In turn, relationships that are less close are those, which at the time, were not perceived as valuable to the business and with which communication was seldom.

The network depictions are star-shaped, ego centric formulations. The qualitative coding of closeness is structurally conveyed in the location of the node on the diagram. The closeness coding of each entrepreneur-within each set - was then aggregated to inform where the node should be placed on the diagram. Ties drawn from the nodes to the central entrepreneur portrayed the visual distance of each relationship.

This inner ring hosts the relationships considered very valuable and communicated with very frequently. The 'inner-most' circle reveal the most obvious contrast between 
depictions. The network of Entrepreneur Set I shows the innermost circle to be occupied with multiple types of relationships as well as a large number of each. In fact, the bulk of relationships within this network reside within the first and second concentric circle. In contrast no nodes relationally reside within the 'inner-most' circle of the of Entrepreneur Set II. The closest relationships border on the second and third concentric circles from the center.

With the first set of entrepreneurs, a variety of bond and bridge relationships constitute the close hub of their network within which the central entrepreneur is situated. The coding of data regarding relationships with similar entrepreneurs revealed two distinct relationships depicted by circular-shaped nodes. They were labeled as peer bonds and mentor bonds. The shortness of their distance from the central entrepreneur suggests that clothing entrepreneurs appeared to frequently communication with entrepreneurs of the same industry.

Peer bonds refer to those relationships with similarly small firms in the fashion industry. The relatively large visual conveyance of peer bonds suggests that clothing entrepreneurs have many relationships with other clothing entrepreneurs. Frequent and casual interaction with peer bonds would offer the pleasant and inspiring exchange of ideas for fashion innovation. Data confirmed this as the microbusinesses interviewed attested to constant engagement in both formal (i.e. fashion shows) and informal settings (i.e. shared studio or workspaces). Charged by personal exchanges ranging from prevailing ideas of youth identity, politics, and global trends to the sharing of newly-founded sources for materials or exhibit shows, peer bonds provided a space where emerging entrepreneurs' dreams and creativity could be shared. In these relationships clothing entrepreneurs would experience the artistic freedom to explore all boundaries of design with their peers- regarding which combination of colors and fabrics alongside the controversial formulation of collective symbolism and meaning creation that would shape garments that speak to South Africa's dynamic marketplace. Peer bonds were most valuable when they were constructive and trustworthy, as some entrepreneurs also acknowledged a competitive spirit and information hoarding behavior that would occasionally manifest between entrepreneurs of the fashion industry.

Mentor bonds described ties with more advanced fashion designers. Entrepreneurs would often attest to holding apprenticeships in the studios of established designers during the early stages of their career. In this relationship, they spoke to gaining invaluable knowledge in the technical and artistic skill of the garment creation process as they contributed directly to the value chain of innovation and production in their mentor's shop. Furthermore, they would gain insights in how to run the business side of the clothing manufacturing sector. The initial stages of the apprenticeship would entail small contributions of design and assembly from the young entrepreneurs. As they would mature in their development, their responsibilities within the shop would increase, from overseeing components of the design process to producing whole fashion lines or managing the general business activity of the organisation.

Square-shaped nodes in the network structure depict bridging relationships, or those that connect the central entrepreneur to groups that have dissimilar attributes. Several relationship types with a bridging quality were coded from the data regarding entrepreneurs of dissimilar industries and immigrant entrepreneurs. The data revealed a relational type labeled communal bridges - those relationships exhibiting such visible closeness to the central entre-preneur, often in the arrangement of a close-knit circle of high trust and familiarity. The high frequency of interaction that these relationships offered were often enabled by the close physical proximity between entrepreneurs. Entrepreneurs would describe the buzzing and gregarious environment of work and friendship formed within buildings that have several studios and workspaces belonging to small enterprises from different fields or the opening of an entrepreneur's shop to others within which a communal space of co-creating, exchange, and relating in life and passion was made. Hence, through these enjoyable exchanges, relationships would grow and people valued each beyond the potential contribution they could offer to one's business growth alone. Such an atmosphere of trust and 
respect served to forming business partnerships in launching new, unprecedented initiatives. In this regard the growing entrepreneur is becoming more privy to the opportunities of innovation and collaboration that exists with working alongside the likes of entrepreneurs from all angles of artistic expression as well as those in sectors such as transportation, catering, and event planning. The culture of treating each other as 'family' built the expectation of freely sharing information and sharing creative ideas with one another without fear of duplication. A supportive and more secure environment augmented through the familial atmosphere cultivated the assurance that one's innovations and originality would be respected. The environment also encourages increased sense of world awareness.

When asked to describe their relationship with immigrant entrepreneurs (interpreted as nationals from other African countries), clothing entrepreneurs consistently referred to a process of consulting immigrant entrepreneurs for production assistance or a specialised skill. They referred to this process as 'outsourcing.' Such insight led to the conceptualisation of the outsource bridge.

As apparent in the network diagram, the outsource bridge also holds close ties to entrepreneurs of the first set, and in sizeable number. Often, clothing entrepreneurs from other countries have specialised skills - such as embroidery, buttoning, or cloth painting - which are common in their respective countries' clothing and fashion industry. Additionally, they often possess specialised machinery such as an embroidery machine. Furthermore clothing microbusinesses experience a surplus of demand which their production capacity cannot bear alone, risking poor workmanship, late delivery, and the loss of clientele. In both these circumstances, South African clothing entrepreneurs would seek the services of immigrant entrepreneurs.

Immigrant entrepreneurs gradually play an essential role in the communal bridging process as they contribute to a culture of a receptive, open, and diverse exchange. Hence, the value of their ties is drawn from the mutual assistance and sense of security naturally fostered by these intimate business relationships. Participating in the hub of information by which entrepreneurs access less expensive supplies and other artisans with specialised skill, they represent another relationally driven resource. Such relationships are particularly operationally valuable as they would relieve the small entrepreneur's burden of performing all the work 'in house' as well as enabling the high level production without bearing the legal implications and financial obligations of hiring workers for which they may not have the capacity.

Collaborative bridges, a relationship represented by another square-shaped node of high closeness to the central entrepreneur, refers to the ties between entrepreneurs who would take on business opportunities in the form of combined production assets and joint agreements. In contrast to communal bridges, as the data suggest, collaborative bridges are based more upon the project and appear to be much less intimate. They were not apt to be described in terms of friendships and family as communal bridges were. Rather, they appeared to strictly serve an income-generating purpose - increasing capacity for joint agreement so as to increase productivity or to provide means of expansion or diversification for the small clothing enterprise. Hence the primary value of collaborative bridges with entrepreneurs of a different line of business is related to increased productivity. By combining resources and production capacities, small businesses are able to provide for markets of greater demand and compete at levels at which, by themselves, they would be less able. Small businesses continue to acquire knowledge of new trends and techniques as they begin to engage with these new market opportunities. Furthermore, via this collaboration, small businesses acquire means by which to engage with potential partners and gain access to unfamiliar markets and new business activities.

On the other hand, the general NDS of service entrepreneurs depicts a relatively smaller network, in terms of the numbers and diversity of relationships, and a looser network, where relationships qualitatively conveyed a farther distance from the central entrepreneur. In sharp contrast to the network of clothing entrepreneurs, the bulk of relationships which constitute the inner-circle of closely positioned ties did not exist within the service entre- 
preneurial NDS. Service entrepreneurs made nearly no reference, for example, to the need and/or recognition of high trust, close knit entrepreneurial spaces within which small firms of different industries engage in a collaborative creation process, as depicted in the communal bridges within clothing entrepreneurs' networks. Rather, the data conveyed that service entrepreneurs appear to work largely independently, and source support from each other on a need-basis. The qualitative relational dimension of entrepreneurial engagement that appeared to be of such high value to clothing entrepreneurs did not emerge in the data of service entrepreneurs. Outsource bridges - also a highly prominent tie of the clothing entrepreneurs' NDS - appeared not to be as evident among service entrepreneurs' networks. Data presented little evidence that a close relationship between service entrepreneurs and immigrant entrepreneurs in terms of shared production was a common occurrence. The occasional mentioning of immigrant entrepreneurs suggested relationships on a friendly basis, but very little on production- or capacity-building value. Outsourcing as a general practice was not frequently mentioned among service microbusinesses to substantiate a conceptual relationship, although some entrepreneurs did mention the occasional hiring of freelance work to carry a project on to completion.

\subsection{Network diversity structure of service entrepreneurs (Set II)}

So then, what did the structure of network diversity among service entrepreneurs convey? From first glance, the obvious distinction is that the network diagram depicts nodes to be structurally farther from the central entrepreneur in set II than in set I. Nonetheless, relationships which were positioned the closest - and hence valued highly and communicated with frequently - were those with larger entities and institutions, namely government and larger corporations. This observation is an intriguing contrast to clothing entrepreneurs, where the closest relationships were with similarly sized firms of the same or different industry.

The data conveyed that these particular ties for service entrepreneurs mostly take place in the form of sub-contracting. The triangularshaped nodes represent a tie with an institution. A linkage with governmental institutions that is of particular closeness to service entrepreneurs was coded the public agency linkage. This tie represents a connection with a government agency, often times facilitated through the awarding of tenders. Service entrepreneurs also spoke of how they sought to be placed on government databases so as to be consulted in time of needed services that they may provide. Similarly, corporate client bridges represented relationships with larger businesses where the microbusiness was hired to provide a precise service towards the company's overall value chain. Both ties were deemed as highly valued ties because they provide a small firm with the opportunities to become part of larger production chain hosted by a bigger organisation, and hence, an entrance into the industry. Additionally, public incubator linkages - government-related or funded business development services, also represent one of the closer positioned nodes as service firms affirmed their high valued provision of skills and training to increase the effectiveness of their firms.

Relationships such as the corporate client bridge or public agency linkage held a position of moderate closeness within the network structure of the clothing entrepreneurs. Only those fashion entrepreneurs who had the capacity to manage voluminous orders considered doing business with larger firms as a positive contribution to their businesses' growth. Hence, the ability of small clothing firms to engage in contractual agreements as suppliers of mass-produced garment goods to corporate clients appeared to be a function of business capability and maturity. The same is the case with ties with government agencies. Unlike service entrepreneurs, only a few clothing entrepreneurs perceived public agency linkages - relationships in which clothing entrepreneurs were suppliers to government agencies - as valuable, suggesting clothing entrepreneurs formed these relationships under certain conditions or at a particular time in the development of their capabilities. Instead, the closer links that clothing entrepreneurs had with government were more in the form of personal ties, codes as public official linkages. 
Public official linkages refer to a relationship whereas individual government officials and their affiliates (i.e. spouse, friends) are direct purchasers - and hence, provide useful input towards the development of - the designer's creation.

Comparatively, financial linkages and global bridges appear to be relationships of least closeness for both entrepreneurial groups. Although both groups of entrepreneurs expressed their desire to connect to parties overseas - to whom they could distribute their goods or extend their services - and to secure financing from banks, the reality held that to maintain either relationship was difficult. Having few acquaintances in other countries and not having consistent access to internet served as two critical reasons for the low value and communication infrequency of global bridges. The unproven viability of most entrepreneurs interviewed appeared to be a deterrence to securing formal financial credit.

\section{5}

\section{Discussion and conclusion}

The analysis has revealed a nuanced conceptualisation of relationships beyond the simplification of bonds, bridges, and linkages in order to capture the contextual features within which the innovation process is embedded. Clothing microbusinesses frequently communicate with a combination of ties across similar and dissimilar entrepreneurs. Within this exchange is a reiterative process of sharing ideas and inspiration towards the creation of the product. Further, data described an innovation process that goes beyond the conceptualisation of design. The synergistic combining of resources and capacities also lend to the innovation of mutually beneficial processes by which small firms can achieve the multiple goals of producing high quality, niche products that meet a burgeoning demand beyond their individual capacities. As a result, participating entrepreneurs in the innovation process would collaboratively secure a revenue stream from which both draw income. These ties of the 'inner circle' would vary in their relational closeness, and range in perception as 'friends and family' to the collegial but more product-driven partnerships. Either way, these distinct attributes of the clothing entrepreneur constituted a dynamic innovation process supported by the closeness of these diverse relationships. On the other hand, data from entrepreneurs in the service sector does not speak of this on-going engagement of collaborative creation. Their network structure qualitatively - and hence visually - appears to be more dispersed. Their 'closest' ties were those with institutions and larger organisations. Even in these relationships, the coded data revealed only a moderate frequency of interaction and very little on co-creation or collaboration. Arguably, the innovation process may be hampered by the established bureaucracy of such organisations that allow limited space for bargaining, negotiating, or creating meaning of multiple sources of knowledge and experience. Consequentially, such ties provide the great value in presenting opportunities of entering the industry by which a small enterprise of emerging capacity, can become an integrated component of an established organisation's value chain with a proven competitive advantage.

Hence, the primary gain is that innovation is a highly socially embedded process within a network structure of close, diverse ties. Moreover, the central argument posed that qualitative, intangible, and experiential aspects of closeness - fostered by the structural composition of closeness - is critical in fostering the innovation process as well.

The findings were generally supported by the literature on networks and firm innovation. Overall, the literature supports a generally positive relationship between networks and innovation, which Pittaway et al. (2004) confirm through their comprehensive systematic review of both conceptual and empirical works. Tsai (2001) highlights that network position does have a positive impact on innovation, mediated by the actor's capacity to absorb the knowledge gained externally. Lipparini \& Sobrero (1994) bring particular attention to small and medium enterprises, as they argue that small enterprises can use their relational capabilities to find new combinations of knowledge and further competitive advantage beyond the limitations of their size. Similarly, this study confirms such insight by exploring the interaction between network 
structure and sector, while keeping the firm size constant. Future studies that examine how the link between the variation in firm size and sector informs networks of innovation value has useful implications for business development (Rogers, 2004).

The specific attention given to the structural closeness of an entrepreneur's network as an innovation-enabling attribute resonates with findings of those such as Schilling \& Phelps (2007), who emphasise the reach and cluster of a firm's relationships as significant contributors to the innovation process. The reach - referring to the capacity to access diverse actors and a wider array of knowledge, and cluster - referring to the positioning of nodes that permit the high degree of exchange and information - bear semantic variation but conceptual resemblance to the noted ideas of diversity and closeness in this study. Swan, Newell, Scarbrough, and Hislop, (1999) echo the imminent value of having actors in spaces of close proximity so as to facilitate consistent engagement and exchange.

Nonetheless, the 'relational' or 'experiential' closeness that diverse actors of a network share is a very distinct dimension from that of the 'structural' closeness. This study would argue that it is the structural closeness that creates the environment conducive to the cultivation of the relational closeness. And as mentioned, this study argues that it is within this qualitative, intangible experience of closeness that the innovation between actors is spurred and facilitated. Swan et al.'s (1999) study of community-based networking affirms this logic by highlighting the collaborative cocreation and negotiation of knowledge that enables institutionally-defying innovation of people working together. According to Blomqvist \& Levy (2006), this engagement demands the prerequisite of a 'collaborative capacity' that describes the genuine activation of trust, commitment, and communication in participating actors - in order to optimise the interactions taking place in the network.

Ahuja's (2000) empirical work, however, reminds us that different aspects of an entrepreneur's network can provide contradictory aspects to an entrepreneur's innovation process. Although this was not a prevalent theme that emerged from the data, a few respondents occasionally mentioned a competitive, rather than collegial, attitude between entrepreneurs. This aspect was acknowledged as a social and attitudinal dimension of the entrepreneurial community that could influence innovation in adverse ways and is worthy of further exploration.

The proposed argument presents alternative insights to two respected assertions presented in the economic sociology literature. First, Granovetter's strength of weak ties argument has long been revered and is foundational in the social embeddedness literature (1973). Granovetter postulates that ties beyond one's immediate identity group, allow an actor to access a variety of information that aids in their economic advancement. The findings from this study suggest that among microbusinesses in this emerging market setting, different types of ties provide different types of economic value, rather than asserting that one type of tie has more economic value than another (Ahuja, 2000). Hence, the qualitative findings from this study suggest that close ties - which would be considered 'strong ties' in Granovetter's study, and in turn, not as economically potent - actually have innovationoriented value towards the economic success of microenterprises. "Strong ties" of highly perceived value and high frequency of communication provide a space of continual exchange, inspiration, and combined capacities as all parts of the co-creation process.

A second assertion of Abigail Barr (2002) suggested that, in lieu of studying the network use of Ghanaian manufacturing firms, there is a difference depending upon the firm size. She argues that large firms draw innovative value from their networks, whereas small firms ideally source security from their web of relationships. The South African case presented here argues that the dichotomy between 'secure' and 'innovative' networks is to be further interrogated. Rather, this study suggests that the innovation process is embedded and driven by a sense of secure relationships those fueled by a high sense of trust, relateability, and mutual respect.

Such structural and relational emphasis of closeness, and closeness with diverse nodes, as a network attribute which promotes innovation confirms that innovation is indeed an 
embedded process (Oerlemans, Meeus, \& Boekena, 1998). This study emphasises that 'closeness' has a very distinct qualitative interpretation in the relational understanding of small enterprises' networks beyond just calculated distance or structural position. "Closeness" captures an intangible and yet extremely meaningful set of relational variables that spark not only a sense of mutual appreciation between people or organisations, but moreover, the desire to work together, to expose inner thoughts and ideas, to entrust to each other future ambitions or current struggles. It is a particular dimension of relational capital that embodies the elements of deep meaning and helps to create the experiences and memories created by entities every time they engage. And such 'closeness' depicts not only a static relational attribute, but that which has the potential of converting into economic value, as the ability to mutually envision, design, and build translates into collaborations around niche products, reputeable brands, quality production, and operational efficiency that gives a firm of any size an endearing and competitive advantage.

\section{References}

AHUJA, G. 2000. Collaborative networks, structural holes, and innovation: a longitudinal study.

Administrative Science Quarterly, 45:425-455.

BAKKER, R.M., OERLEMANS, L.A. \& PRETORIUS, M.W. 2008 . Domestic and international innovation partnerships : do they matter for innovation outcomes of South African firms? South African Journal of Economics:518-536.

BARR, A. 1995. The missing factor: Entrepreneurial networks, enterprises, and economic growth in Ghana. Working paper no. 1995-11, CSAE Working Paper Series. Oxford: Center for the Study of African Economies. University of Oxford.

BARR, A. 2002. Social capital and technical information flows in the Ghanaian manufacturing sector. Oxford Economic Papers:539-559.

BLOMQVIST, K. \& LEVY, J. 2006. Collaboration capacity - a focal concept in knowledge creation and collaborative innovation in networks. International Journal of Management Concepts and Philosophy, 2: 31-48.

BRUCE, M. 2003. Ethnic entrepreneurship: Preliminary findings from a South African study. Journal of Small Business and Entrepreneurship:47-62.

CHEN, C.-H. 2009. Constructed network as social capital: The transformation of Taiwan's small and medium enterprise organization. In R.-M. Hsung, N. Lin, \& R.L. Breiger (eds.) Contexts of social capital (pp. 139149). New York: Routledge.

DOBBIN, F. 2004. The sociological view of the economy. In F. Dobbin (ed.) The new economic sociology: A reader (pp. 1-48) Princeton: Princeton University Press.

FAFCHAMPS, M. \& MINTEN, B. 2002. Returns to social network capital among traders. Oxford Economic Papers:173-206.

GARCIA, M.S. 2006. Social capital, networks, and economic development. Cheltenham: Edward Elgar. GIDDENS, A. 1986. The constitution of society: outline of the theory of structuration. Volume 349. University of California Press: Berkeley, CA.

GITTELL, R. \& VIDAL, A. 1998. Community organizing: Building social capital as a development strategy. Thousand Oaks: Sage Publications.

GLASER, B. \& STRAUSS, A. 2007. The discovery of the grounded theory: strategies for qualitative research. New Brunswick, New Jersey: Aldine Transaction.

GRANOVETTER, M. 1973. The strength of weak ties. American Journal of Sociology, 78(6):1360-1380. GREVE, A. \& SALAFF, J. 2003. Social networks and entrepreneurship. Entrepreneurship Theory and Practice:1-21.

GRANOVETTER, M. 1985. Economic action and social structure: the problem of embeddedness. American Journal of Sociology, 91(1985):481-93.

GROOTAERT, C., NARAYAN, D., JONES, V. \& WOOLCOCK, M. 2003. Measuring social capital: an integrated questionnaire. Washington, D.C. The World Bank Publications. 
HITE, J. \& HESTERLY, W. 2001. The evolution of firm networks: from emergence to early-growth of the firm. Strategic Manaement Journal, 22:275-286.

HOANG, H. \& ANTONCIC, B. 2003. Network-based research in entrepreneurship: a critical review. Journal of Business Venturing, 18:165-187.

HUMAN, G. 2009. Measuring network competency in buyer-supplier relationships. South African Journal of Economics and Management Sciences, 12:429-447.

KLYVER, K., HINDLE, K. \& MEYER, D. 2008. Influence of social network structure on entrepreneurship participation: A study of 20 national cultures. International Entrepreneurial Management:331-347.

KUADA, J. 2009. Gender, social networks and entrepreneurship in Ghana. Journal of African Business: 85-103.

LIPPARINI, A. \& SOBRERO, M. 1994. The glue and the pieces: entrepreneurship and innovation in small firm networks.. Journal of Business Venturing, 9:125-140.

LU, J.W. \& BEAMISH, P.W. 2001. The internationalization and performance of SMEs. Strategic Management Journal:565-586.

LUO, J.D. 1997. The significance of networking in the initiation of small businesses in Taiwan. Sociological Forum:297-317.

MÄKELÄ, M. \& TURCAN, R.V. 2007. Building grounded theory in entrepreneurship research. In H. Neergaard \& J. P.Ulhoi (eds.) Handbook of Qualitative Research Methods in Entrepreneurship. Edward Elgar Publishing:122-143.

MCDADE, B. \& SPRING, A. 2005. The new generation of African entrepreneurs: Networking to change the climate for business and private-sector led development. Entrepreneurship \& Regional Development:17-42. MEAGHER, K. 2006. Social capital, social liabilities, and political capital: social networks and informal manufacturing in Nigeria. African Affairs:553-582.

NAUDE, W. \& HAVENGA, J. 2005. An overview of African entrepreneurship and small business research. Journal of Small Business and Entrepreneurship:101-119.

OERLEMANS, L., MEEUS, M. \& BOEKENA, F. 1998. Do networks matter for innovation: the usefulness of the economic network approach in analyzing innovation. Royal Dutch Geographical Society, 89:298-309. Blackwell Publishers.

PINGLE, V. 2001. Identity, landscapes, social capital, and entrepreneurship: Small business in South Africa. Center for Policy Studies. Johannesburg.

PITTAWAY, L., ROBERTSON, M., MUNIR, K., DENYER, D. \& NEELY, A. 2004. Networks and innovation; a systematic review of the evidence. International Journal of Management Review, 5/6(3/4): 137-68.

PORTES, A. \& SENSENBRENNER, J. 1993. Embeddedness and immigration: Notes on the social determinants of economic action. The American Journal of Sociology:1320-1350.

PORTES, A. 1998. Social capital: Its origins and applications in modern sociology. Annual Review of Sociology:1-24.

ROGERS, M. 2004. Networks, firm size, and innovation. Small Business Economics, 22:141-153.

RUTASHOBYA, L.K., ALLAN, I.S. \& NILSSON, K. 2009. Social networks, and entrepreneurial outcomes in Tanzania. Journal of African Business:67-83.

SCHILLING, M. \& PHELPS, C. 2007. Interfirm collaboration networks: the impact of large scale network structure on firm innovation. Management Science, 53:1113-1126.

SPENCE, L., SCHMIDPETER, R. \& HABISCH, A. 2003. Assessing social capital: Small and medium size enterprises in Germany and the U.K. Journal of Business Ethics:17-29.

STANDARD AND POOR. 2008. Global Industry Classification Standard. Available at: http://www.standardandpoors.com/indices/gics/en/au [accessed June 2013].

STRAUSS, A. \& CORBIN, J. 1990. Basics of qualitative research: grounded theory procedures and techniques. London: Sage Publications.

STUART, T. \& SORENSON, O. 2005. Social networks and entrepreneurship. In S. Alvarez, R. Agarwal, \& O. Sorenson, Handbook of Entrepreneurship Research: Disciplinary Perspectives (pp. 233-252). New York : Springer Science Business Media, Inc. 
SWAN, J., NEWELL, S., SCARBROUGH, H. \& HISLOP, D. 1999. Knowledge management and innovation: networks and networking. Journal of Knowledge Management, 3:262-275.

TSAI, W. 2001. Knowledge transfer in intraorganizational networks: effects of network position and absorptive capacity on business unit innovation and performance. Academy of Management Journal, 4(5):996-1004.

URBAN, B. 2011. Social capital configuration for necessity-driven versus opportunity-drieven entrepreneurs. South African Journal of Economic and Management Sciences, 14:407-421.

WOOLCOCK, M. 1998. Social capital and economic development: toward a theoretical synthesis and policy framework. Theory and Society:151-208

WOOLCOCK, M. \& NARAYAN, D. 2000. Social capital: Implications for development theory, research and policy. The World Bank Research Observer:225-249.

WOOLCOCK, M. 2002. Social capital in theory and practice: Where do we stand? In J. Isham, T. Kelly, \& S. Ramaswamy. Social capital and economic development well-being in developing countries. Cheltenham: Edward Elgar:18-39.

YEUNG, H. 1997. Business networks and transnational corporations: a study of Hong Kong firms in the Asean region. Economic Geography, 73(1):1-25.

YLI-RENKO, H., AUTIO, E. \& SAPIENZA, H. 2001. Social capital, knowledge acquisition, and knowledge exploitation in young technology based firms. Strategic Management Journal, 22(6/7):587-613.

ZHOU, L., WU, W. \& LUO, X. 2007. Internationalization and performance of born global SMEs: The mediating role of social networks. Journal of International Business Studies, 38(4):673-690. 